\title{
Model Proposal for Future Estimates in Maritime Industry: The Case of Container Handling in Turkish Ports
}

\author{
(1) Ünal Özdemir \\ Mersin University Faculty of Maritime, Department of Maritime Business and Management, Mersin, Turkey
}

\begin{abstract}
Future planning is difficult in several industries, including the maritime sector, especially with the current pandemic because of numerous active dynamic factors. Thus, this study aimed to determine the freight demand estimates based on the Twenty-foot Equivalent Unit-based monthly number of containers handled in Turkish ports by comparing the prediction accuracy and reliability of artificial neural network (ANN) models with various algorithms using the "exponential smoothing" and "Box-Jenkins" time series methods. The monthly container volume handled in Turkish ports between January 2005 and December 2018 was used, and augmented Dickey-Fuller tests were conducted with the EViews 5 software. Results from several tests revealed that the 12-time delay ANN model, which was developed with the original series, provided the highest accuracy. In this study, the demand forecasts for the container volume that would be handled in Turkish ports were conducted for the year 2022 with the developed model, and a methodological approach was presented for the forecast models in different maritime industry fields.
\end{abstract}

Keywords

Container, Maritime commerce, Artificial neural networks, Time series, Turkey

\section{Introduction}

Container shipping is one of the most important international shipping industry structures. Several products are transported with container shipping and annual reports demonstrate its growth every year in Turkey and globally [1]. The vessel capacity in container shipping routes is estimated to be approximately 253 million tons per vessel and will increase by $1-2 \%$ with new vessel orders $[1,2]$. The container movements around the world were reported to be about 750 million Twenty-foot Equivalent Unit (TEU) as of 2019 [1,3]. Furthermore, the global container demand increased by $3.2 \%$ between 2012 and 2018, 2.5\% between 2012 and 2016, and $4.7 \%$ between 2016 and 2019, exhibiting a positive differentiation compared to other shipping modes [1,3-5]. Having a similar development with the global market, the Turkish foreign trade comprised $86 \%$ of the Turkish market, in which 387 million tons were shipped by sea routes in 2018. In these periods, the preference for container modes in the Turkish maritime freight and Turkish exports was about $20 \%$ and $33 \%$, respectively [6]. This high global container shipping volume could be attributed to important factors including the suitability of this mode for intermodal transport and its availability for port-to-port, door-to-door, and between different delivery points [7-10].

With the expansion of supply chains, the role of ports has gradually increased and port operations have become more complex. The fact that the ports are facing strong competition requires the improvement of services provided by port authorities and operators. The survival of these businesses in a globally competitive environment most importantly relies on the more effective utilization of business structures, understandings, and scientificbased forecasting models. Therefore, rapid environmental changes should be followed continuously and carefully, and port management strategies should be developed according

Address for Correspondence: Ünal Özdemir, Mersin University Faculty of Maritime, Department of Maritime

Received: 01.11.2020 Business and Management, Mersin, Turkey

E-mail: unalozdemir@mersin.edu.tr ORCID ID: orcid.org/0000-0001-6865-9977

To cite this article: Ü. Özdemir, "Model Proposal for Future Estimates in Maritime Industry: The Case of Container Handling in Turkish Ports," Journal of ETA Maritime Science, vol. 9, pp. 13-21, 2021.

${ }^{(C)}$ Copyright 2021 by the Journal of ETA Maritime Science published by UCTEA Chamber of Marine Engineers 
to these changes. People tasked with making decisions in maritime transports have to make the best business choices and plans as quickly as possible. More importantly, these decisions need to be accurate to avoid heavy losses that are very difficult to reverse. The process of predicting the future of ports is also complex and several criteria must be considered. Therefore, before making investments and future plans, decision makers should be able to create these complex relationship networks with scientific estimation and modeling techniques to quickly obtain results and accurately predict the effects of the decisions made on the results [10-13].

Container shipping is reported to be an ideal, economical, and safe transportation mode for overseas, high-tonnage, and various types of cargo $[14,15]$. Furthermore, it is considered as an important investment tool for national economies through strategic partnerships in container trades, improvement of container shipping productivity, advantages of the economies of scale, and distribution of financial costs and risks [16-19]. However, there exists a race to increase the market share among national competitors. Thus, nations could make a difference in the container lines to enter in new markets, provide intermodal services, and develop value-added products and services. Countries compete for the highest share in container shipping to acquire a stronger strategic position in the foreign exchange and freight revenues. Initially, two countries compete in a region to increase their share in container shipping, which is the most active mode of maritime transportation. The ports of the regional competitors try to improve their positions in this race and achieve a more advantageous position. In Turkey, three main routes exist for container transportation: (1) the transatlantic (between Europe and Americas), (2) the transpacific (between Asia and Americas), and (3) the Eurasian line (between Europe and the Far East) [20]. Turkey is located on the Eurasian maritime line between the Far East and Europe and in the northern Transport Corridor Europe-Caucasus-Asia project because of its low miss distance [21], which is a very advantageous position. The development of a higher freight demand and increasing its contribution to the economies of scale would be possible with careful analysis of the dynamic processes [22]. Because of the fragile structure of the maritime industry where global risks always prevail, focusing on multidisciplinary studies and future estimates and models would reduce these risks. The global pandemic is an appropriate example of events that could adversely affect the delicate dynamics of the maritime trade. This study aims to develop realistic forecast models with a different approach based on the container volume handled in Turkish ports (based on total TEU) to provide an exemplary model for container shipping, which is an essential building block in the maritime industry, and to provide realistic estimates for the future. This study also aims to contribute to the management of Turkish ports in possible future dynamic processes for 2022 . The availability of scientific data will increase the competitiveness of the Turkish maritime industry in the global container shipping market. The findings of the study will reveal the current status of the industry in this process. Similar to the current study, scientific estimates aim to overcome future risks based on national strategic plans and future visions. Thus, the present study aims to determine the freight demand estimates based on the TEU-based monthly number of containers handled in Turkish ports by comparing the prediction accuracy and reliability of artificial neural network (ANN) models with various algorithms using the "exponential smoothing" and "Box-Jenkins" time series methods. Consequently, certain recommendations are presented.

\section{Methodology}

The present study aims to construct a hybrid prediction model with ANNs, exponential smoothing, and Box-Jenkins methods. The methodological methods are presented below.

\subsection{Artificial Neural Networks}

In literature, ANNs are described as computing systems that could provide solutions for statistical, mathematical, decision-making, risk management, and philosophical problems to accomplish a task or a goal through a combination of numerous neurons based on certain rules $[23,24]$. In general, ANNs produce new information based on previously learned or coded information and data by imitating the human nervous system [25,26]. ANNs are frequently employed in software in several fields such as prediction models, robotic applications, signal processing, energy efficiency, and nonlinear control [27-30].

There are three inputs in an ANN algorithm, i.e., the neuron (called the artificial neural cell), connections, and learning diagram. The artificial neural cell is the main element of the ANN algorithm [27]. Neurons in the ANN algorithm receive one or more inputs based on the inputs that affect the problem and provide an expected number of outputs based on what the problem requires. The ANN algorithm is developed by connecting the artificial nerve cells. In ANN algorithms, a cluster of neurons in the same direction forms the layers [23,29]. Figure 1 shows an ANN algorithm model.

\subsection{Exponential Smoothing Method}

In contrast to the simple moving averages (MAs) method where the historical data have equal weights, the exponential smoothing method can be described as a collection of methods similar to the simple MAs method. However, 
the simple MAs method assigns different weights to the historical data compared with the exponential smoothing method [31,32]. This means that the weights assigned as exponential terms decrease exponentially as the existing inputs get older. In the exponential smoothing method, the historical data, which are generally used for prediction, are assigned higher weights when they are relatively recent and the assigned weight decreases as the data get older [33,34].

In this method, determining the smoothing coefficients that would provide the lowest mean squared error for the algorithm is a very important step. In general, the method includes a combination of different techniques based on the characteristics $[32,33,35]$. These methods include the single (simple) exponential smoothing method, Brown's single parameter linear exponential smoothing method, Holt's double parameter linear exponential smoothing method, and Winters' seasonal exponential smoothing method. In the literature, the Winters' seasonal exponential smoothing method is preferred in the prediction of the inputs that are under the influence of trends and seasonal variations. This method includes four equations to smooth the three inputs for each algorithm, namely the data dependent on trends, random, and seasonal variations [36,37]. These 4 equations are given below:

$$
\begin{aligned}
& K_{p}=Q \frac{M_{p}}{R_{p-r}}+(1-Q)\left(K_{p-1}+b_{p-1}\right) \\
& b_{p}=ß\left(K_{p}-K_{p-1}\right)+(1-\beta) b_{p-1} \\
& R_{p}=y \frac{L_{p}}{K_{p}}+(1-y) R_{p-r} \\
& R_{p+a}=\left(K_{p}+b_{p} a\right) R_{p-r+a}
\end{aligned}
$$

Where " $\mathrm{R}$ " is the number of seasons in a year, " $K_{p}$ " is the general level of the current series in period " $p$ ", " $b_{p}$ " is the trend input, " $R_{p}$ " is the seasonal component, and " $R_{p+a}$ " is the forecast for future period "a". " $Q$ ", " $\beta$ ", and " $y$ " are the Winters' method's smoothing constants; " $Q$ " is the average smoothing constant in the model, " $\beta$ " is the trend smoothing constant, and " $y$ " is the seasonal smoothing constant.

\subsection{Box-Jenkins Method}

The Box-Jenkins algorithm is generally known as a hybrid of the "autoregressive (AR)" and "MA" methods, and it is widely applied in various fields. The main objective of the Box-Jenkins technique is to develop a linear model with the most ideal and lowest number of data in the time series [38]. One of the most important advantages of this method is its ability to provide an ideal solution without focusing on whether the series is static or whether there are seasonal effects [33,39]. These models, which constitute the main structure of the Box-Jenkins method, include the non-seasonal and seasonal models. Thus, BoxJenkins technique is also called AR integrated MA method (ARIMA) in the literature [37]. The non-seasonal BoxJenkins models are generally described as ARIMA (p,d,q) $(\mathrm{P}, \mathrm{D}, \mathrm{Q})_{\mathrm{S}^{\prime}}$, where "P" refers to the degree of the seasonal AR (SAR) model, " $D$ " is the number of seasonal variance operations, " $Q$ " is the degree of the seasonal MA (SMA) model, and " $S$ " is the seasonal period. In the seasonal ARIMA algorithm in (P,D,Q) degrees, the backward shift operator is expressed as given in Equation 5 is below.

$\theta_{p}\left(A^{L}\right) \Delta_{L}^{M} X_{c}=\sigma_{\exists}\left(A^{L}\right) \in_{c}$,

where " $\Delta_{L}$ " denotes the seasonal difference operator and " $L$ " denotes the seasonal periods, which is given a value of " 12 " for a monthly data. " $\Delta^{M "}$ denotes that the seasonal difference was taken " $M$ " times. After the transformations are conducted for all the operators in the system, the stationarity of the series is ensured and the non-stationary series is accepted

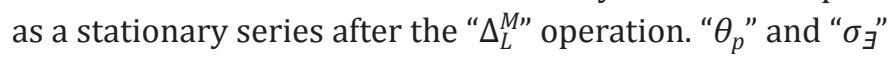
refers to the SAR and SMA, respectively.

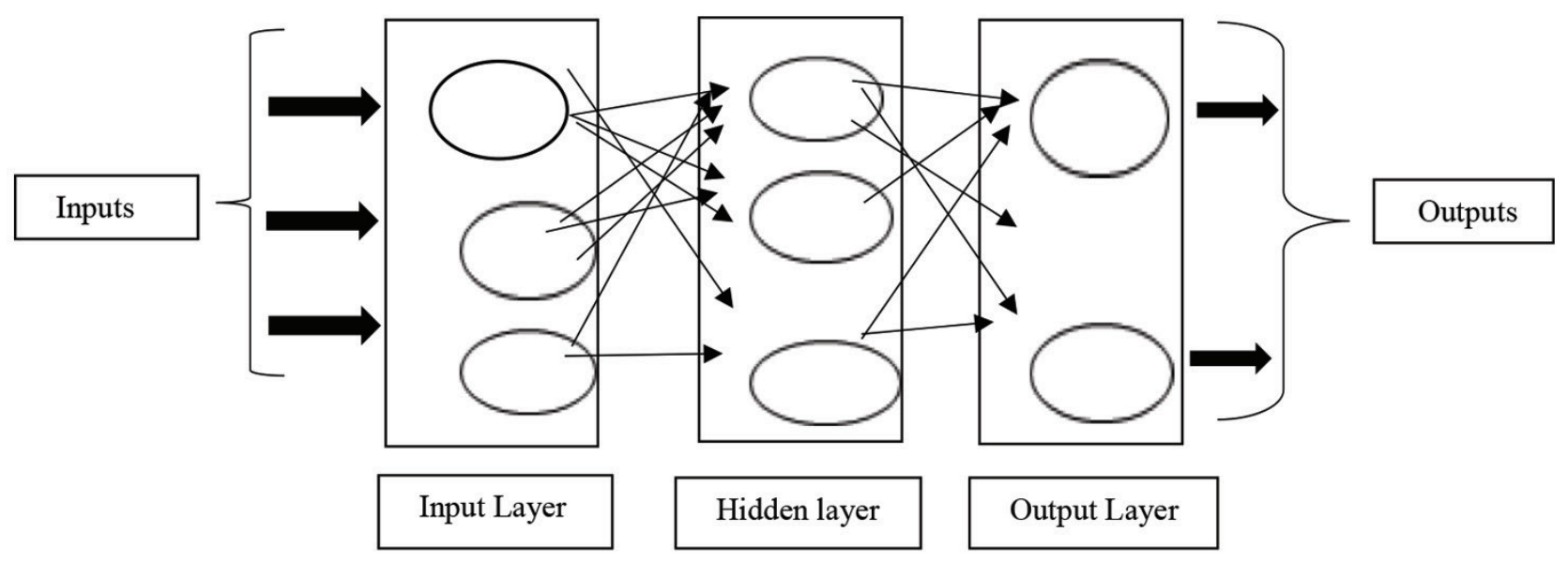

Figure 1. An artificial neural network algorithm model 
In this technique, the current data values are based on the combination of the weighted sum of the previous data and random shocks. Thus, in the determination of the model, the stationarity of the series and the presence of the seasonal effects are the differentiating criteria. Therefore, the features of the time series used in the first stage should be determined and an ideal model approach should be adopted. In this method, a four-step iterative approach is preferred to determine the ideal approach among all model combinations. These four steps include the determination, parameter estimation, fitness tests, and prospective estimation stages. When the approach determined in the process is not at a desired level, the process is repeated until another model, which is developed to improve the original model, provides a satisfactory result $[33,37,39]$.

\section{Case Study}

This study aimed to develop the freight demand estimates using the monthly container volume handled in Turkish ports (based on TEU) with the most reliable model determined through the comparison of the prediction accuracy and reliability of ANN models with different algorithms based on the time series models of exponential smoothing and Box-Jenkins techniques. This study used the monthly container volume handled in Turkish ports between January 2005 and December 2018.

\subsection{Study Data}

The total container volume handled in Turkish ports between January 2005 and December 2018 was analyzed. In the literature, the total handling volume is considered among the most important productivity data for the ports. Moreover, the demand in container ports is measured with the total container volume handled in the ports in the literature $[15,18,38,40]$. The data for the container volume handled in Turkish ports were obtained from statistics reports published by the Ministry of Transportation and Infrastructure. The total monthly data were analyzed for the specified period. A monthly data was selected to conduct more detailed analyses based on the seasonal and trend variables.

\subsection{The Research Method}

In the first phase of the study, the main factors that affected the series were determined with the analysis of the properties of the time series data for determining the adequate techniques for the collected data. In the next phase, the January 2005-December 2018 data were used to forecast the monthly container volumes that would be handled in the Turkish ports in 2021 and 2022 (JanuaryDecember) using the models that are suitable for the data along with the ANN models with exponential smoothing and Box-Jenkins methods. The forecasts were compared with the actual container handling figures to determine the most realistic and ideal model. The prediction accuracy of the applied algorithms was tested with the "mean absolute percentage error (MAPE)" statistics. The fact that the MAPE statistics expresses prediction errors as a percentage is considered as a superiority when compared to other criteria because of its standalone meaning in the literature $[26,28,39,41-45]$. In previous studies, the accuracy of the prediction models is classified according to their MAPE values: (1) highly accurate, MAPE $<10 \%$; (2) accurate, MAPE is between $10 \%$ and 20\%; (3) acceptable, MAPE is between $20 \%$ and 50\%; and (4) inaccurate, MAPE >50\% $[26,34,39,40,43,44]$. Equation 6 represents the MAPE algorithm.

$$
M A P E=\frac{\sum_{k=1}^{r} \frac{\left|b_{k}\right|}{z_{k}}}{r} 100(\%) \text {. }
$$

When $b_{k}=z_{k}-\hat{z}_{k}$ for $z_{k}=k^{\prime \prime}$ period, $\hat{z}_{k}=k$ is the calculated estimate for the period, " $r$ " is the number of estimated periods, and $b_{k}=k$ is the prediction error in the period.

\subsubsection{Determination of Time Series Components}

The time series was analyzed in the study. The analysis of the data for 168 months in Figure 2 (January 2005-December 2018) revealed an increasing trend and that the data were affected by the seasonal fluctuations. The fluctuation started increasing in March in successive years and reached the maximum in August and September. The lowest fluctuations were observed in January. The source of fluctuations is assumed to be because of the seasonal trade effects.

\subsection{Application of the Methods}

In this section, the forecasts conducted with exponential smoothing, Box-Jenkins techniques, and ANNs are addressed. Due to the increasing trend of the study data and the impact of seasonal fluctuations, the adequate time series methods, i.e., the "seasonal exponential smoothing" and "seasonal Box-Jenkins" methods were used.

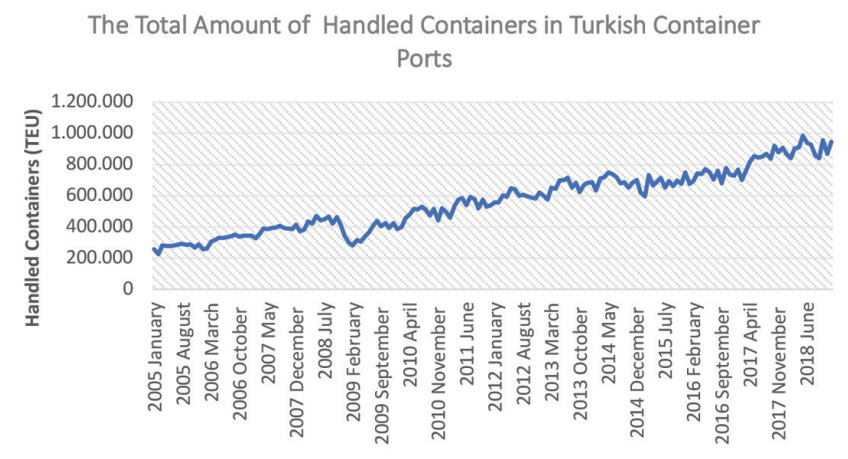

Figure 2. Analysis of the data for January 2005-December 2018 TEU: Twenty-foot Equivalent Unit 


\subsubsection{Seasonal Exponential Smoothing (Winter's) Method}

The technique was applied with SPSS 22.0 statistics software. Seasonal index values obtained with seasonal deconstruction were employed as seasonal factors. The smoothing constant " $Q$ ", trend smoothing constant " $\beta$ ", and seasonal smoothing constant " $y$ " parameters in Equations $1,2,3$, and 4 were determined to minimize the square sum of errors in the model. Based on the calculations, $\mathrm{Q}=0,8000000, \beta=0,000000$, and $y=0,000000$ were used as the smoothing coefficients in the model. The initial model values were calculated with the software and the following were determined: $K_{r}=51764,15324$ (initial level) and $b_{r}=231,025421$ (initial trend).

\subsubsection{Seasonal Box-Jenkins Method}

The initial application of the Box-Jenkins technique determined that the seasonal component in the data was not constant with time, and the natural logarithm of the data was taken to include seasonal variations in the original data. Stationarity analyses were conducted with the augmented Dickey-Fuller (ADF) tests. The results revealed that the series was stationary after the first-order seasonal difference was taken $(D=1, S=12)$. Autocorrelation and partial autocorrelation functions of the data were analyzed, and the seasonal and non-seasonal AR and MA degrees were obtained. The adequate range for AR, MA, seasonal $A R$, and seasonal MA was determined to be $p=1$, $\mathrm{q}=0, \mathrm{P}=0$, and $\mathrm{Q}=1$ for seasonal MA. These values revealed that the ideal algorithm for the total container volume handled in the Turkish ports series (based on TEU) that was dependent on a logarithmic transformation was ARIMA $(1,0,0)(0,1,1)_{12}$, the "multiplicative-seasonal ARIMA Model." The final parameter estimates for the developed model are presented in Table 1. All t-values associated with the parameter estimates of the algorithm presented in the table were statistically significant at " 0.00 " significance level (furthermore, seasonal parameter estimates provided $|t|>1.25)$.
After the statistical analysis conducted on the data estimates of the model, the "Ljung-Box $\left(Q^{*}\right)$ " statistics method was used to test whether the residuals of the model were random (white noise) and whether there was autocorrelation between them. The " $Q *$ " statistics calculated based on the $14^{\text {th }}, 26^{\text {th }}$, and $38^{\text {th }}$ delays for the residual series of the model demonstrated that there was no significant autocorrelation between the residuals; the residual series had a random function, and the algorithm was suitable. Box-Jenkins models were applied with autocorrelation and partial autocorrelation functions, and ADF tests were calculated with EViews 5 software, which is a statistical package software for the Windows operating system and frequently used especially for econometric analysis. It has a unique programming language that combines the spreadsheet and relational database infrastructure with the features of traditional statistical software. Although EViews can also be used for general statistical analysis, it is preferred especially in regression analysis and econometric analysis. Panel data, time series, and cross-section analysis can be done with EViews.

\subsubsection{Artificial Neural Networks}

In the stage where the study data was modeled with ANNs, the prediction performances of various ANN algorithms developed with three datasets were analyzed. Out of the 198 monthly parameters, 180 were categorized as training data for the $2003-2018$ period and 18 were categorized as test data for the January 2019-June 2020 period. Various time lag data " $\left(z_{k-1}, z_{k-3}, z_{k-12} \ldots z_{k-u}\right)$ " were employed in the input layer, and the data without lag " $\left(z_{k}\right)$ " were employed in the output layer. The calculations were conducted with the neural networks' module (Neural Network Toolbox) of the MATLAB 7.0 software. The study data were first normalized for the [0:1] range and then employed in the software. The data were normalized with Equation 7 given below.

Table 1. ARIMA $(1,0,0)(0,1,1,)_{12}$ model parameter estimates

\begin{tabular}{|c|c|c|c|c|}
\hline Variable & Estimate & Standard error & t-statistics & p-value \\
\hline AR (1) & 0.72165303 & 0.05021743 & 16.503121 & 0.00000000 \\
\hline SMA (1) & 0.50349610 & 0.04976017 & 9.341063 & 0.00000000 \\
\hline Number of observations & \multicolumn{4}{|c|}{267} \\
\hline Number of observations after noticing & \multicolumn{4}{|c|}{255} \\
\hline Sum of error squares & \multicolumn{4}{|c|}{18.010030} \\
\hline Standard error & \multicolumn{4}{|c|}{0.26013218} \\
\hline Converting and difference & \multicolumn{4}{|c|}{ The seasonal first difference of the series whose Napierian logarithm is taken ( $\mathrm{s}=12)$} \\
\hline
\end{tabular}


$Y_{n}=\frac{Y_{0}-Y_{\min }}{Y_{\max }-Y_{\min }}$

where " $Y_{0}$ " is the original data, " $Y_{n}$ " is the normalized data, " $Y_{\min }$ " is the smallest number in the dataset, and " $Y_{\max }$ " is the greatest number in the dataset.

For the analyzed datasets, models with different hidden layers (between 1-5) and different neurons (between 1-5) were constructed in the study. The training was conducted with experiments with various iterations $(5,000-50,000)$. All models were then tested with the data reserved for testing. The predictive accuracy of ANN models with different algorithms was measured by comparing the predicted figures with the actual figures.

Several tests were conducted, and the predictive accuracy and reliability of the models were observed to decrease with increasing number of neurons in the hidden layer and the number of neurons in the hidden layer of the tested models. The twelve-lag model gave the most accurate results among the different ANN models. Because the systematic pattern (seasonal cycle) in the datasets repeated every twelve months, the twelve-lag models yielded better results compared to the one- or three-lag models. There was an input, a hidden, and an output layer in the model with six neurons, three neurons, and one neuron, respectively. Figure 3 represents the related ANN model.

A feedforward-backpropagation network algorithm was used in the constructed model, the logarithmic sigmoid algorithm was selected as the activation function and the Levenberg-Marquardt algorithm was selected as the training function, and 30,000 epochs (epoch: single feedforward in an ANN) were conducted in the model training.

\section{Findings}

To determine the ideal model and algorithm for the prediction of the TEU-based total container volume handled in Turkish ports in the future, the accuracy measurements

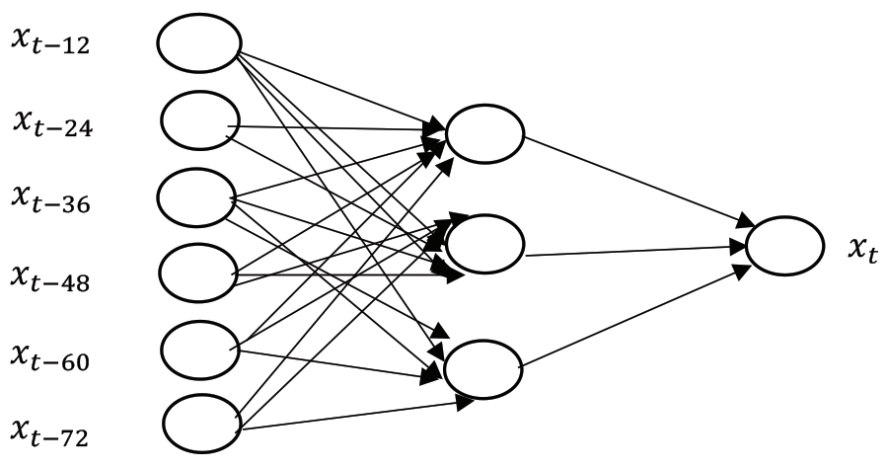

Figure 3. The ANN design

ANN: Artificial neural networks conducted on the predicted figures with the analyzed methods and actual figures were analyzed. Table 2 presents the related data.

ANNs showed highest prediction accuracy and provided the closest results to the actual figures. ANNs could learn nonlinear correlations between the parameters and generalize the findings, thus answering questions that were never encountered before within an acceptable margin of error. Due to these features, the ANN method was preferred in forecasts.

As discussed in Section 3.2, the models with a MAPE value $<10 \%$ were classified as "very good", those between $10 \%$ and $20 \%$ were classified as "good", those between $20 \%$ and $50 \%$ were classified as "acceptable", and those $>50 \%$ were classified as "inaccurate" in the literature. The figures presented in Table 2 show that in the predictions obtained with the ANNs and multiplicative-seasonal Box-Jenkins techniques, the "MAPE" figures were $<10 \%$, whereas the seasonal exponential smoothing (Winters) method had a MAPE value of $12.97 \%$. This suggested that all three techniques provided accurate predictions. Among these methods, the Winters' seasonal exponential smoothing method was the most preferred because it could be employed for the data that exhibit trends and parameters with seasonal fluctuations. Furthermore, the Box-Jenkins model techniques are frequently employed in the literature because they require no additional data for prediction and have proven to yield short and medium-term prediction accuracy in previous studies. In addition, their ability to determine the ideal model among various models and test the suitability of the determined model for the parameters in every process emphasizes the significance of these methods. However, the 12-lag ANN techniques were observed to exhibit low deviation compared to the seasonal exponential smoothing and Box-Jenkins method findings. The comparison of the prediction accuracy of the analyzed techniques demonstrated that the ANN model with the [5-3-1] order led to the most reliable result. Thus, this technique was preferred for the prediction of the total container volume handled in Turkish ports for 2022 based on TEU. Table 3 presents the data analysis findings for this technique.

Table 2. Prediction accuracy of analyzed techniques

\begin{tabular}{|c|c|}
\hline Techniques & MAPE (\%) \\
\hline Artificial neural networks & 6.03 \\
\hline Box-Jenkins ARIMA $(1,0,0)(0,1,1)_{12}$ & 8.53 \\
\hline Seasonal exponential smoothing (winters) & 12.97 \\
\hline $\begin{array}{c}\text { MAPE: Mean absolute percentage error, ARIMA: Autoregressive integrated } \\
\text { moving average method }\end{array}$ \\
\hline
\end{tabular}




\section{Conclusion and Recommendations}

Proactive predictions in the maritime industry based on scientific approaches would facilitate future economic policies and national strategies and allow more realistic forecasts. Demand is the main factor for investments in the maritime industry, and the investments are a function of the quantitative and qualitative attributes of demand. In the maritime industry, the investments require a very high budget, and the success of policies and projects depends on the forecast of future demands and market structures, thus matching the supply resources and demands. Realistic and reliable demand forecasts are a prerequisite for efficient organization of all operational activities, primarily the ship routes, port infrastructures, maritime logistics network, and national maritime policies. Thus, determining adequate techniques for the properties of the analyzed parameters that reveal the most accurate and reliable predictions for future demand is important. The present study aimed to determine the model with the highest reliability in predicting the total monthly and annual container volume handled in Turkish ports based on TEU by comparing the prediction accuracy of ANN models that included different algorithms with time series methods of exponential smoothing and Box-Jenkins. Analysis of the findings demonstrated that the ANNs method exhibited the highest prediction accuracy and provided the closest results to the actual figures. ANNs could learn nonlinear correlations between the parameters and generalize the findings, thus answering questions that were never encountered before within an acceptable margin of error. Because of these features, the ANN method was preferred in forecasts. Based on both the present and

Table 3. Predictions for monthly container handling in Turkish ports in 2022

\begin{tabular}{|c|c|}
\hline Months (year 2022) & $\begin{array}{c}\text { Total number of containers to be } \\
\text { handled (TEU) }\end{array}$ \\
\hline January & 897246 \\
\hline February & 887524 \\
\hline March & 975256 \\
\hline April & 1098214 \\
\hline May & 1010245 \\
\hline June & 1089624 \\
\hline July & 1174526 \\
\hline August & 1078562 \\
\hline September & 970952 \\
\hline October & 987452 \\
\hline November & 1005877 \\
\hline December & 921485 \\
\hline \multicolumn{2}{|c|}{ TOTAL } \\
TEU: Twenty-foot equivalent unit
\end{tabular}

previous results, ANN models without problems, such as overtraining and incorrect algorithm development, provided better results compared to the models constructed with other methods. In the literature, ANN algorithms provide highly effective results in nonlinear and dynamic models. On the other hand, the model does not allow the interpretation of the problems in contrast with the statistical methods. Moreover, the model remains a closed box for the results obtained with ANNs. The total monthly and annual container volume handled in Turkish ports for 2022 was predicted with the ANNs' technique whose reliability was tested in the present study. A similar study was also conducted by Gökkuş et al. [45] that discussed the ports of Izmir, Mersin, and Istanbul for 2023 using the past records of the gross domestic product, exports, and population of Turkey as indicators of socioeconomic and demographic status. For the testing period, their study reported that the LSSVM, ANN-ABC, and ANN-LM models performed better than the MNR-GA model considering overall fitting and prediction performances of the extreme values in the testing data. In contrast to the study of Gökkuş et al. [45], several tests conducted in our study revealed that the 12-time delay ANN model, which was developed with the original series, provided the highest accuracy. The fact that the dynamic factors are always active in the maritime industry, especially during the current pandemic, and the inability to predict the future increases the value of related studies such as the present research. Now, with the proposed model, reliable and flexible solutions can be provided to decision makers. The adaptation process of this method to the problem and the obtained results show that the method is simple, intelligible, and useful enough for the maritime sector. As a solution, quantitative method approaches are considered to be very effective in solving complex problems in the maritime sector, this helps in obtaining a more concrete cluster of alternatives and reaching more realistic solutions. The main limitation of our study is related to the characteristic of the examined container port in Turkey. Turkish container ports have the characteristic of being a transit port because they are located on the main shipping routes, which necessitates the consideration of the transportation consisting transit loads. Hence, the data set of the study is limited to Turkish container ports.

In future studies, ANN models with different algorithms could be employed to predict the container volume, general cargo load, liquid bulk cargo, number of passengers, etc. Furthermore, national, regional, or port vessel arrivals; the average length of stay in the ports; the average duration of handling operations in the ports; could be predicted in future studies. The forecast performances of hybrid models that combine ANNs and time series prediction methods could 
also be determined. Thus, considering the limited number of studies conducted with ANNs and hybrid approaches in maritime commerce, the above-recommended studies would significantly contribute to future planning studies by maritime industry personnel and decision makers. Because no similar study is available in the maritime literature, the present study would guide researchers who plan to conduct future studies in the field.

Funding: The author declared that this study received no financial support.

\section{References}

[1] UNCTAD, Review of Maritime Transport 2019. United Nations Publications, eISBN 978-92-1-004302-1, New York, United States of America. 2019.

[2] C.. Polat, and F. Merdivenci, "Evaluation of line selection criteria of freight forwarders in container transportation," Turkish Journal of Maritime and Marine Sciences, vol. 5, pp. 112-126, 2019.

[3] J. Garriddo, S. Sauri, Á. Marrero, Ü. Gül, and C. Rua, "Predicting the future capacity and dimensions of container ships," Transportation Research Record: Journal of the Transportation Research Board, vol. 2674, pp. 177-190, June 2020.

[4] I. Wagner, "Transportation \& Logistics", Global Container Market, 2018. Available: www.statista.com

[5] N.K. Park, and S.C. Suh, "Tendency toward mega containerships and the constraints of container terminals," Journal of Marine Science and Engineering, vol. 7, pp. 1-13, Feb 2019.

[6] WTO, (2019), "World Trade Report" 2019. Available: https:// www.wto.org/english/res_e/booksp_e/00_wtr19_e.pdf

[7] C.. Iris, J. Christensen, D. Pacino, and S. Ropke, "Flexible ship loading problem with transfer vehicle assignment and scheduling," Transportation Research Part B: Methodological, vol. 111, pp. 113-134, Feb 2018.

[8] V. Kannan, S. K. Bose, and N.G. Kannan, "An evaluation of ocean container carrier selection criteria: An Indian shipper's perspective," Management Research Review, vol. 34, pp. 754-772, Jun 2011.

[9] P. Kolar, H. J. Schramm, and G. Prockl, "Intermodal transport and repositioning of empty containers in central and eastern europe hinterland," Journal of Transport Geography, vol. 69, pp. 73-82, May 2018.

[10] H. Bendall, and A. F. Stent, "Investment strategies in market uncertainty," Maritime Policy \& Management, vol. 30, pp. 293303, May 2010.

[11] H. M. A. Meersman, "Port investments in an uncertain environment," Research in Transportation Economics, vol. 13, pp. 279-298, 2005.

[12] C. Solak Fıșkın, E. F. Akgül, and Ç. Karataș Çetin, "Liman rekabetçiliğini etkileyen faktörler: Ege bölgesi konteyner terminalleri kullanıcılarına yönelik bir VZAHP uygulaması," Dokuz Eylül Üniversitesi Denizcilik Fakültesi Dergisi, vol. 8, pp. 1-23, Jan 2016.

[13] Z. Peng, H. Wang, W. Wang, and Y. Jiang, "Intermodal transportation of full and empty containers in harbor-inland regions based on revenue management," European Transport Research Review, vol. 11, pp. 7, Jan 2019.
[14] A.Çalışkan, and Y.Öztürkoğlu, "Evaluation offinancial performance of container lines with respect to operational qualifications," International Journal of Economic and Administrative Studies, ISSN 1307-9832, pp. supple 123-134, Feb 2020.

[15] S. Theofanis, and M. Boile, "Empty marine container logistics: facts, issues and management strategies," GeoJournal, vol. 74, pp. 51-65, 2009.

[16] K. Shintani, R. Konings, and A. Imai, "The impact of foldable containers on container fleet management costs in hinterland transport," Transportation Research Part E, vol. 46, pp. 750-763, Sep 2010.

[17] T. Glave, M. Joerss, and S. Saxon, "The hidden opportunity in container shipping", McKinsey \& Company, pp. 1-14, Nov 2014.

[18] N. K. Tran, and H. D. Haasis, "An empirical study of fleet expansion and growth of ship size in container liner shipping." International Journal of Production Economics, vol. 159, pp. 241253, Jan 2015.

[19] İ. Temiz, Ü. Özdemir, and N. J. Ece, "Avrupa-Kafkasya-Asya ulaşım koridorunda yer alan Samsun limanı'nın verimlilik analizi,” Türk Denizcilik ve Deniz Bilimleri Dergisi, vol. 4, pp. 93-105, 2018.

[20] A. Ateș, Ş. Karadeniz, and S. Esmer, “Dünya konteyner taşımacılı̆̆ı pazarında Türkiye'nin yeri,” Dokuz Eylül Üniversitesi Denizcilik Fakültesi Dergisi, vol. 2, pp. 83-98, Jun 2010.

[21] S. Karakaş, A.Z. Acar, and M. Kırmızı, "Development of a multidimensional performance evaluation model for container terminals at Marmara Sea", Research in Transportation Business \& Management. vol. 37, pp. 100498, Dec 2020.

[22] G. Ciaburro, and B. Venkateswaran, "Neural networks with R: Smart models using CNN, RNN, deep learning, and artificial intelligence principles", Birmingham: Packt Publishing. ISBN: 978-1-78839-787-2. Sep 2017.

[23] H. Kumar, and, S. Giri, "Flow shop scheduling algorithm based on artificial neural network," Bulletin of Pure and Applied Sciences, vol. 38, pp. 62-71, 2019.

[24] S. K. Safi, "Comparison of artificial neural network and time series models for forecasting gdp in Palestine," American Journal of Theoretical and Applied Statistics, vol. 5, pp. 58-63, 2016.

[25] A. M. R. Cancela, "Comparative study of artificial neural network and box jenkins arima for stock price indexes," ISCTE Business School, Mastering Data Analysis Prospecting. Sep 2008.

[26] G. Xie, B. Sunden, Q. Wang, and L. Tang, "Performance predictions of laminar and turbulent heat transfer and fluid flow of heat exchangers having large tube-diameter and large tube-row by artificial neural networks," International Journal of Heat and Mass Transfer. vol. 52, pp. 2484-2497, May 2009.

[27] M. Khashei, and M. Bijari, "A novel hybridization of artificial neural networks and ARIMA models for time series forecasting," Applied Soft Computing, vol. 11, pp. 2664-2675, Mar 2011.

[28] J. Li, R. Wang, J. Wang and Y. Li, "Analysis and forecasting of the oil consumption in China based on combination models optimized by artificial intelligence algorithms," Energy, vol. 144, pp. 243264, Feb 2018.

[29] A. L. Katsatos, and K. P. Moustris, "Application of artificial neuron networks as energy consumption forecasting tool in the building of regulatory authority of energy, Athens, Greece," Energy Procedia, vol. 157, pp. 851-861, Jan 2019. 
[30] K. S. Vaisla, and A. K. Bhatt, "An analysis of the performance of artificial neural network technique for stock market forecasting," International Journal on Computer Science and Engineering, vol. 2, pp. 2104-2109, 2010.

[31] J. J. F. Commandeur, and S. J. Koopman, "Introduction to state space time series analysis", Illustrated Edition, Kindle Edition, Format: Kindle Edition, 2013.

[32] E. Montanes, J. R. Quevedo, M. M. Prieto, and C. O. Menéndez, "Forecasting time series combining machine learning and Box-jenkins time series," Conference: Advances in Artificial Intelligence - IBERAMIA 2002, 8th Ibero-American Conference on AI, Seville, Spain, Nov 12-15, 2002, Proceedings.

[33] A. H. Nury, K. Hasan, and J. B. Alam, "Comparative study of Wavelet-ARIMA and Wavelet-ANN models for temperature time series data in Northeastern Bangladesh," Journal of King Saud University-Science, vol. 29, pp. 47-61, Jan 2017.

[34] T. W. Anderson, The Statistical Analysis of Time Series, John Wiley and Sons. Inc, New York. 1971.

[35] S. Sharawei, An Introduction to Modern Time Series Analysis, King Abdulaziz University, Saudi Arabia, 1st edition. 2005.

[36] N. Garg, M. K. Sharma, K. S. Parmar, K. Soni, R. K. Singh, and S. Maji, "Comparison of ARIMA and ANN approaches in time-series predictions of traffic noise." Noise Control Engineering Journal, vol. 64, pp. 522-531, Jul-Aug 2016.

[37] G. Box, and G. Jenkins, Time Series Analysis Forecasting and Control, San Francisco Helden-Day, 1976.
[38] M. Çuhadar, İ. Güngör, and A. Göksu, "Forecasting tourism demand by artificial neural networks and time series methods: a comparative analysis in inbound tourism demand to Antalya," Süleyman Demirel University The Journal of Faculty of Economics and Administrative Sciences, vol. 14, pp. 99-114, 2009.

[39] G. Gao, K. Lo, and F. Fan, "Comparison of ARIMA and ANN models used in electricity price forecasting for power market," Energy and Power Engineering, University of Strathclyde. Glasgow, UK, vol. 9, pp. 120-126, Apr 2017.

[40] S. Esmer, S. Alnıpak, and O. Duru, "Port productivity assessment for major container terminals of Turkey," International Journal of Transport Economics, vol. 46, pp. 112-135, Dec 2019.

[41] I. Akgül, Zaman Serilerinin Analizi ve ARIMA Modelleri, Der Yayınları, 2003, İstanbul.

[42] C.D. Lewis, Industrial and Business Forecasting Methods: A Practical Guide to Exponential Smoothing and Curve Fitting, Butterworths Scientific, Publishing: London, 1982.

[43] SF. Witt, and C. Witt, "Modeling and forecasting demand in tourism," Academic Pres, 1992, London.

[44] O. Duru, and S. Yoshida, "Judgmental forecasting in the dry bulk shipping business: statistical vs. judgmental approach," The Asian Journal of Shipping and Logistics, vol. 25, pp. 189-217, Dec 2009.

[45] Ü. Gökkuş, M. S. Yıldırım, and M. M. Aydın, "Estimation of container traffic at seaports by using several soft computing methods: a case of Turkish Seaports," Discrete Dynamics in Nature and Society, 2017. 